\title{
A tela dos dispositivos Android: um percurso de pesquisa sobre design responsivo
}

The displays of Android devices: a search path for responsive design

\section{César Steffen}

UNIRITTER - Centro Universitário Ritter dos Reis

cesar@steffen.net.br

PROJËTICA

\section{COMO CITAR ESTE ARTIGO:}

STEFFEN, César. A tela dos dispositivos Android: um percurso de pesquisa sobre design responsivo. Projética, Londrina, v. 11, n. 2, p. 15-34, 2020.

DOI: 10.5433/2236-2207.2020v11n2p15

Submissão: 10-07-2017

Aceite: 08-07-2019 
RESUMO: Os dispositivos Android apresentam uma grande variação no formato e definição das telas. Ao contrário do principal concorrente, Apple, cujo sistema IOS é instalado apenas nos dispositivos produzidos pela marca, o que garante a padronização nas telas e interfaces, o sistema Android pode ser utilizado por vários fabricantes de dispositivos móveis diferentes, que definem formatos e padrões de tela para os seus dispositivos móveis, sejam tablet ou telefones celulares. Isto impacta diretamente no projeto de design das telas de um aplicativo para o sistema Android, uma vez que deve prever e antecipar esta diversidade de formatos, buscando ofertar a melhor experiência para o usuário. O design responsivo busca ofertar respostas a tais problemas, ofertando técnicas que possibilitam elaborar telas que ofereçam para o usuário uma excelente experiência de visualização, contato e interação em uma ampla variedade de dispositivos diferentes. Assim, este estudo foca em compreender as etapas de projeto necessárias para a construção de um aplicativo para dispositivos móveis com sistema operacional Android, de forma a obter a melhor resposta do usuário, através do design responsivo. Para tanto, busca sua base metodológica no estudo de caso descritivo, não somente pela novidade representada pelos aplicativos para dispositivos móveis e pela amplitude e flexibilidade na análise ofertada por tal instrumento, mas principalmente de forma a descrever o comportamento e os resultados gerados pelos aplicativos nas diferentes telas.

Palavras-chave: Design responsivo. Android. Projeto de interface. User experience.

ABSTRACT: Android devices show a wide variation in the display size and resolution. Unlike its main competitor, Apple, whose IOS is installed only in the devices produced by them - which ensures standardization in the displays and graphic interface - the Android system can be used by several different mobile device manufacturers that define their own standards, whether for tablets or cell phones. This directly impacts on the layout design of applications for the Android system, since it must consider and anticipate the diversity 
of display specs, aiming to deliver the best user experience. Responsive design seeks to answer such problems, applying techniques that allow the layout design to provide the user with the optimal experience of visualization, contact and interaction in handling a wide variety of different devices. Thus, this study focuses on understanding the design steps required to build an application for mobile devices running the Android operating system, in order to achieve the best response from the user through responsive design. To do so, this paper's methodological basis is grounded on a descriptive case study, not only for the novel approach it allows to mobile applications and for the wide range and flexibility of analysis it provides, but mainly to describe the behavior and results achieved by the applications in displays with different specification.

Keywords: Responsive design. Android. Interface design. User experience.

\section{INTRODUÇÃO}

A história da evolução das tecnologias de informação e comunicação não é somete a história da evolução das pesquisas e da tecnologia, mas principalmente a história da evolução das demandas humanas frente a tecnologia. Desde a máquina de Babbage e das tabuladoras Hollerith, passando pelos computadores analógicos (FRAGOSO, 2002) e chegando até os tablets atuais, a tecnologia reflete a necessidade humana de utilização e apropriação de elementos no sentido de ampliação do alcance de seus sentidos e de sua participação e interferência no ambiente que que vive.

A pá amplia a força da mão ao cavar; a câmera fotográfica ou de vídeo amplia o olhar; o telefone amplia a voz e a audição (MCLUHAN, 2012; PERRIAULT, 1991); e as tecnologias móveis somam todas estas potencialidades, colocando praticamente todos os recursos tecnológicos e as linguagens de todas as mídias

- TV, rádio, jornal, revista, fotografia, etc. - permanentemente ao alcance dos usuários. 
As interfaces gráficas dos computadores, que tem no Apple Macintosh a primeira experiência bem-sucedida, demonstram esta necessidade. A máquina computadorizada deixa de ser uma esfinge tecnológica que requer anos de treinamento para ser utilizada, e passa a, através de ícones e elementos interativos, "falar a linguagem do homem" (FRAGOSO, 2002). E neste ponto está o início do crescimento e explosão do uso doméstico, ou para entretenimento, das tecnologias da informática.

Figura 1 - Quadro esquemático das teorias de $\mathrm{HCl}$

\begin{tabular}{|c|c|}
\hline $\begin{array}{c}\text { usuário como máquina } \\
\text { (deve aprender a falar a } \\
\text { linguagem do computador) }\end{array}$ \\
\hline $\begin{array}{c}\text { computador como mídia } \\
\text { (o computador é um mediador da } \\
\text { comunicação entre pessoas) }\end{array}$ \\
\hline $\begin{array}{c}\text { usuário-sistema } \\
\text { (eng. cognitiva) }\end{array}$
\end{tabular}

Fonte: Fragoso (2002).

Os dispositivos móveis surgem na contemporaneidade como últimos expoentes deste fenômeno, ofertando o acesso rápido e permanente à informação de forma, ao mesmo tempo ofertando entretenimento através de aplicativos e jogos variados. A "inteligência na palma das mãos e na ponta dos dedos" vem atender à necessidade de informação e interação permanente, e traz junto a necessidade de adaptação e colocação da informação de forma adequada a estes suportes.

Somando-se a isto a quase onipresença dos celulares com sistemas operacionais específicos, como Android, IOS e Windows, que ofertam várias e 
variadas funcionalidades além do falar e trocar mensagens, e cujo número de aparelhos cresce exponencialmente, temos um cenário onde a formatação e adequação dos conteúdos aos diferentes dispositivos é uma necessidade para várias empresas, além de uma oportunidade para empreendedores de várias áreas, especialmente design e programação.

Assim, pesquisar e analisar academicamente esta área fornecerá subsídios para o desenvolvimento da área e melhor capacitação dos profissionais e futuros profissionais de design.

\section{ANDROID}

O mundo das tecnologias móveis cresce a cada dia, ofertando cada vez mais liberdade para os usuários de internet. $\mathrm{Na}$ atualidade, temos mais consumidores contratando planos de internet móvel para smartphones do que linhas fixas ou conexões domésticas.

Isto se deve não somente a uma necessidade de acesso permanente a rede, somada ao crescimento das redes sociais, elemento de forte atração para o consumidor Brasileiro, mas também - se não principalmente - a dificuldade de instalação de conexões fixas -cabo ou ADSL - em determinadas regiões, muitas vezes economicamente inviável para as operadoras, que demoram a atender determinadas fatias da população, deixando o campo aberto para as conexões móveis.

A relação dos usuários-receptores com os conteúdos está mudando rápida e drasticamente. A segunda tela durante o contato com materiais de televisão está sendo experimentada em várias redes, de forma a obter mais atenção das pessoas, cada vez mais focada em conteúdos digitais que circulam pelas redes sociais. 0 
comércio mobile começa a mostra sinais de crescimento e amadurecimento, e a utilização de $\mathrm{NFC}^{1}$ e carteiras digitais para pagamentos variados no dia-a-dia já é realidade em países como Japão e Reino Unido.

Mas se esta realidade apresenta grandes oportunidades, traz consigo também grandes desafios. Os diferentes e variadas formatos de telas dos dispositivos, somado aos diferentes sistemas - IOS, Android e Windows - geram o desafio do desenvolvimento de interfaces para sites e aplicativos que sejam flexíveis e possam se adaptar a esta variedade, sem prejuízo para a experiência do usuário. Para dar conta disto surge um novo campo, denominado Design Responsivo, que para ser compreendido nos pede um olhar sobre conceitos que o precedem, como usabilidade.

\section{USABILIDADE}

Usabilidade é um conceito criado para examinar a eficiência, a eficácia e a satisfação que norteiam o entendimento das funções e usos de determinado objeto (NIELSEN; LORANGER, 2007; CYBIS; BETIOL; FAUST, 2010). Neste contexto, entende-se:

- Eficiência: são os recursos cognitivos, ou seja, a inteligência que rege a criação e execução de um projeto;

[1] NFC - Near Field Comunication, tecnologia que permite troca instantânea de dados entre aparelhos que apenas se tocam. Esta tecnologia já pode ser utilizada para pagamento do metrô de Tóquio, por exemplo. 
- Eficácia: é a capacidade de executar tarefas que são próprias de cada objeto, de forma correta e completa, a qualidade particular de determinado produto.

- Satisfação: constitui a reação positiva diante do reconhecimento do efetivo cumprimento das tarefas resultantes da eficiência do projeto e eficácia do produto;

- Função: corresponde aos objetivos que o criador quer dar ao objeto, seja estético, persuasivo, manipulador, transacional e outros, ficando no plano do sensível, ou seja, da emoção, criatividade ou originalidade. É a modalidade subjetiva do agente (criador);

- Uso: está relacionado à atividade funcional do objeto, ao seu fazer, aquele que a cultura lhe dá na vida cotidiana.

Como coloca Donald Norman (2008):

Pessoas normalmente cometem erros durante a utilização de uma série de diferentes produtos. Invariavelmente, elas se sentem culpadas e tentam esconder o erro ou culpar-se por "burrice", falta de prática e ignorância. O que acontece na verdade, é que outros cometem o mesmo erro e isso ocorre em virtude de um design mal feito.

A usabilidade foca na facilidade de aprendizado e de uso de uma determinada interface ou objeto, de forma a que seja o mais rapidamente apreendido pelos usuários em foco. Assim, implica o exame da função comunicativa da interface, foco deste projeto, pois entende-se que nenhuma comunicação traz a verdade, somente mostra a representação do que se pode considerar como verdadeiro. Conforme Jakob Nielsen e Hoa Loranger (2007, p. 15):

É importante perceber que a Usabilidade não é uma propriedade singular, unidimensional de uma interface com os usuários. A Usabilidade tem componentes múltiplos e é tradicionalmente associada com estes cinco atributos: 
1. Ser fácil de aprender;

2. Ser eficiente na utilização;

3. Ser fácil de ser recordado;

4. Ter poucos erros;

5. Ser subjetivamente agradável.

Na busca da perfeita interação do esteticamente e visualmente agradável com o inteligível, prático ou funcional, o projetista da interface deve motivar o usuário a compreender, aprender rapidamente, saber usar o objeto, memorizar sua prática, não cometer erros e, acima e tudo, sentir prazer. Para isto, deve considerar quem são os usuários e quais são as atividades que serão realizadas, bem como onde ocorrerá a interação.

Assim, pode-se otimizar as interações que os usuários realizam com o produto e conteúdo, considerando a diversidade de competências e habilidades, apresentando estratégias que auxiliem sua prática e usar métodos claros, testados e adequados aos diversos níveis de usuários.

Lembrando que o usuário, de forma geral, apresenta resistência ao novo e medo do desconhecido, tem modelos mentais diferenciados e níveis culturais e sociais distintos. Assim, irá apresentar diferentes graus de capacidade para assimilar novas tecnologias, e de preferência irá buscar semelhanças com situações antigas ao lidar com situações novas e inusitadas.

Temos, então, que sistemas ou interface orientados para a usabilidade buscam a máxima facilidade e rapidez de aprendizado na sua utilização, não chamando nenhuma atenção para si mesmos. Da mesma forma, permitem que a informação e navegação fluam naturalmente e geram o entendimento aprofundado do que será apresentado, dos públicos-alvo e da concorrência (benchmark), bem como o discernimento para a organização estratégica das estruturas comunicativas. 
"Pessoas normalmente cometem erros durante a utilização de uma série de diferentes produtos. Invariavelmente, elas se sentem culpadas e tentam esconder o erro ou culpar-se por "burrice", falta de prática e ignorância. o que acontece na verdade, é que outros cometem o mesmo erro e isso ocorre em virtude de um design mal feito". 
Para a obtenção de uma organização eficiente das informações, é preciso levar em conta quais serão relevantes, concisas, persuasivas e facilmente assimiláveis, oferecendo funcionalidades compatíveis com os interesses do usuário. A partir disto, pode-se aplicar códigos, ícones e signos reconhecidos pode diferentes usuários.

Para finalizar, recordamos que a norma ISO/IEC 9126-1 da International Organization for Standardization (2001), utilizada como referência para a avaliação de produtos de software, define seis características de qualidade, desdobradas em sub características. Dentre estas, cita a usabilidade como um dos requisitos, colocando que ISO/IEC: 2001:

“[...] refere-se ao esforço necessário para se utilizar um produto de software, bem como o julgamento individual de tal uso por um conjunto de usuários. Tem como sub características: inteligibilidade, apreensibilidade, operacionalidade, atratividade e conformidade."

ISO/IEC, 2001: refere-se ao esforço necessário para se utilizar um produto de software, bem como o julgamento individual de tal uso por um conjunto de usuários. Tem como sub características: inteligibilidade, apreensibilidade, operacionalidade, atratividade e conformidade.

Ou seja, notamos que obter na tela, na interface do aplicativo, uma organização de elementos que se adaptem ao dispositivo sem - ou com o mínimo de perdas, facilitando a experiência do usuário, apresenta benefícios também para o produtor na medida em que pode aumentar resultados.

Neste ponto atua o design responsivo, não somente trabalhando uma interface de forma a que seja o mais ajustável e agradável, mas também no sentido de estabelecer as prioridades, aquilo que deve aparecer mais nesta interface, 
aplicando as técnicas necessárias para que a tela cumpra seus objetivos junto ao público-alvo.

\section{DESIGN RESPONSIVO}

Em 2010, um profissional de designer focado em atuação para internet - "web designer" - chamado Ethan Marcotte publicou artigo denominado "Responsive Web Design", onde propunha um conjunto de técnicas que garantiam a responsividade de um site. Responsividade, por sua vez e conforme o mesmo autor, trata da qualidade ou possibilidade do design de um determinado site se adaptar às características do dispositivo que está acessando, garantindo ao máximo a qualidade de experiência do usuário. Ethan começa seu artigo citando John Allsopp:

“O controle que os designers têm no meio impresso e, muitas vezes, desejam ter no meio web, é simplesmente um reflexo da limitação da página impressa. Devemos aceitar o fato de que a web não tem as mesmas restrições e projetar (o web design) para essa exibilidade". (ALLSOPP apud MARCOTTE, 2010, grifo nosso).

Em 2011 Ethan lançou o livro de mesmo nome, "Responsive web design", onde aprofundava as bases apresentadas no artigo inicial, e demonstrava os três elementos essenciais para que o design responsivo pudesse ser construído:

1 - Layout fluído, no sentido de utilizar o grid como elemento base de distribuição dos elementos, mas sem a fixação de medidas exatas ou numéricas, no máximo aplicação de proporções, de forma que os elementos possam "se mover" e ajustar conforme a tela;

2 - Imagens e recursos flexíveis, ou seja, aplicação de técnicas para que imagens, vídeos, etc., respondam da mesma forma, se adaptando a distribuição gerada; 
3 - Consultas de mídia, tradução livre de "media queries", conjunto de técnicas que determina os elementos que poderão ser ocultados ou terão sua posição alterada no conjunto de elementos da página, ou seja, que estabelece as prioridades de visualização.

Mas isto pode passar a impressão de que o layout se ajusta exatamente a cada dispositivo e as medidas de sua tela, o que não necessariamente ocorre. Enquanto este estudo é escrito, estima-se que haja, somente para o sistema Android, mais de setenta (70) formatos de telas diferentes a venda no Brasil, sem contar os importados e os dispositivos já fora de linha, que se somados certamente levariam a contagem para acima de duzentos (200), conforme podemos verificar na Figura 2.

Figura 2 - Formatos e dimensões de telas conforme o fabricante do dispositivo

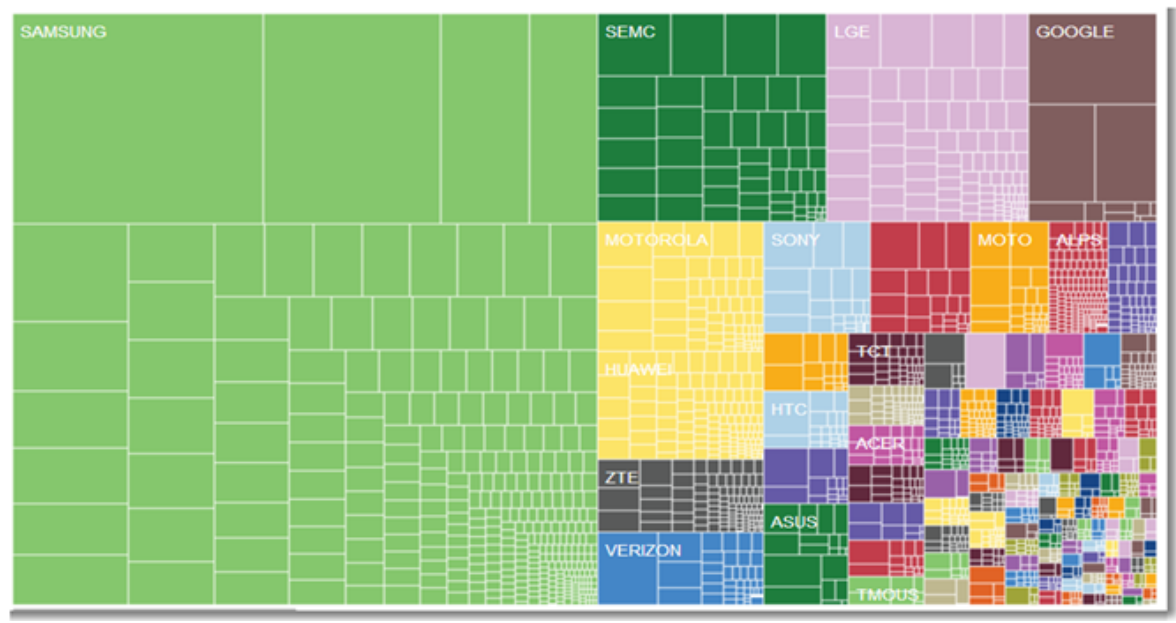

Fonte: Igor Costa $(2014)^{2}$. 
Torna-se, então, praticamente impossível atender as especificidades de cada dispositivo. Por isso, o design responsivo irá focar na resolução da tela, ou seja, no nível de detalhamento e da quantidade de pixels ofertado pelo dispositivo, de forma a que se adapte as diferentes resoluções, sem preocupação direta ou exclusiva com as dimensões (figura 3).

Figura 3 - Exemplo da variedade de proporções de telas de dispositivos Android

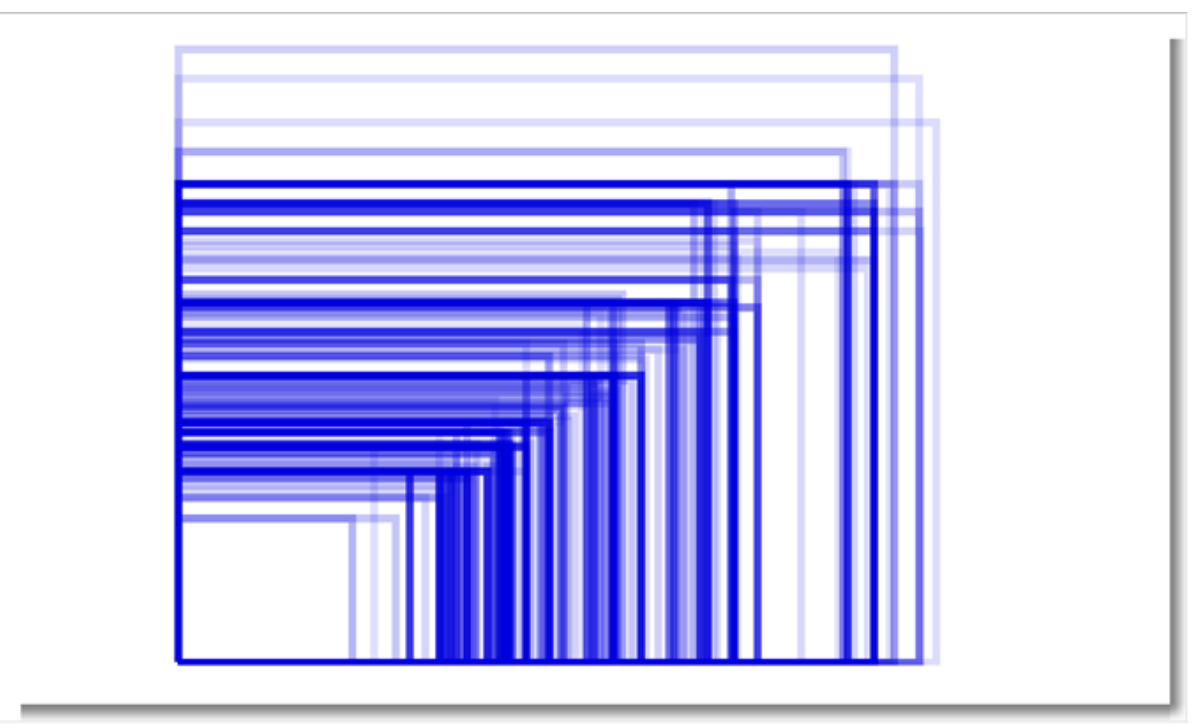

Fonte: Igor Costa $(2014)^{3}$.

A aplicação de linguagens dinâmicas de programação para internet, como HTML 5 e CSS, é essencial para o desenvolvimento e construção de bom design responsivo, mas passaremos ao largo do debate de linguagens de programação, 
uma vez que o foco deste trabalho está na interface, nos conteúdos que o usuário acessa, e não na base tecnológica, não raro invisível para o usuário.

Resumidamente, então, podemos colocar que design responsivo trata da construção e apresentação de telas de sites e aplicativos para vários tipos de dispositivos, no caso do foco deste projeto, smartphones e tablets, podendo ser acessado de qualquer plataforma mantendo uma boa resolução e boa usabilidade, modificando sua organização conforme as características do dispositivo onde está sendo apresentado.

Isto, naturalmente, muda a forma a abordagem de projeto de um aplicativo para dispositivos móveis, pois as técnicas e linguagens empregadas, bem como o design da interface, deverão levar em conta esta capacidade de adaptação. E estas etapas de projeto que esta pesquisa se propõem a observar, utilizando de elementos metodológicos específicos.

\section{METODOLOGIA APLICADA}

Para desenvolver esta pesquisa, cumprindo os objetivos citados, busca-se a base metodológica no estudo de caso descritivo, pela amplitude e flexibilidade na análise ofertada por tal instrumento, e de forma a descrever o comportamento e os resultados gerados pelos aplicativos nas diferentes telas.

Assim, para a formatação da amostragem serão selecionados, aleatoriamente, cinco (5) aplicativos em português, que possuam suporte para diferentes versões do sistema Android que estejam disponíveis na "Play Store", loja de aplicativos do Android, gratuitamente. Estes aplicativos serão instalados em, pelo menos, três (3) diferentes dispositivos, sendo um deles obrigatoriamente um tablet com tela de, pelo menos, oito (8) polegadas. 
Serão capturadas as principais telas de cada um dos aplicativos em todos os dispositivos envolvidos, de forma a construir um banco de imagens que apresente as variações dos elementos visuais e textuais envolvidos nas diversas telas, permitindo a observação das diferenças geradas pela variação dos dispositivos, bem como as ações, estratégias e resultados da aplicação do design responsivo.

Compostos por uma série de elementos visuais e textuais, como fundo, textos, texturas, botões, cores, luzes, etc., a análise das telas tem nos conhecimentos da Gestalt o seu suporte na leitura da relação dos elementos visuais presentes nas telas dos aplicativos e em sua variabilidade nos diversos dispositivos.

Também conhecida como psicologia da forma, as teorias da Gestalt demonstram que o todo é maior que a soma das partes que a constituem. Porém, cada elemento contribui para a percepção deste todo. Assim, é preciso olhar as partes dentro de seu contexto, de modo a compreender seu papel neste todo. $E$, assim, observar como o todo se comporta.

As teorias da Gestalt, especialmente a chamada "escola dualista" desenvolvia na escola da Graz, Áustria, afirma o princípio de que nós, humanos, sempre vemos as coisas dentro de um conjunto de relações, o que afeta nossa forma de percebe-las. Assim, elege uma série de regras e princípio universais de percepção. Esta corrente identifica processos distintos na percepção sensorial, sendo estes a sensação, que corresponde à percepção pura, física dos elementos, e a representação, que seria um processo através do qual os elementos são agrupados e adquirem sentido, a forma visual, que é resultado do trabalho mental do ser humano.

A outra escola da Gestalt, denominada "corrente monista", formada na Alemanha, defendida que sensação e representação se dão simultaneamente, não em separado. A forma não pode ser dissociada da sensação do objeto material, por 
que ocorrem simultaneamente e se completam até a finalização do processo de percepção visual.

Independente desta diferença de observação no interior destas duas escolas quanto a construção da percepção humana, a Gestalt elege as leis da organização, conhecidos também como princípios da Gestalt, que versam sobre o processo de organização da percepção humana, o que seria um comportamento natural do cérebro.

O princípio da proximidade diz que elementos próximos tendem a ser agrupados em um mesmo elemento. O mesmo ocorre no princípio da semelhança, que coloca que elementos semelhantes tendem a ser agrupados em um único conjunto. "Fechamento" mostra que o cérebro humano tem a tendência de completar os elementos.

A boa continuidade foca no alinhamento das formas, mostrado que uma mesmo direção em linhas torna os elementos mais fluídos. Já o princípio da pregnancia diz que todas as formas tendem a ser percebidas em seu caráter mais simples: uma espada e um escudo podem tornar-se uma reta e um círculo, e um homem pode ser um aglomerado de formas geométricas (GOMES FILHO, 2009).

Os fatores de equilíbrio, clareza e a aplicabilidade de uma peça gráfica neste caso, a tela do aplicativo - ou de qualquer manifestação visual constituem para o ser humano uma necessidade, e por isso são considerados indispensáveis na formação de imagens logo, das telas. Equilíbrio, clareza, contraste, figurafundo e pregnancia (figura 4) visual são os elementos em foco para a análise da estrutura de percepção de construção do aplicativo, que permitirão a interpretação dos elementos, de forma a gerar um juízo crítico sobre os resultados em cada dispositivo específico. 
Figura 4 - Grade de Hermann - exemplo do princípio de fechamento

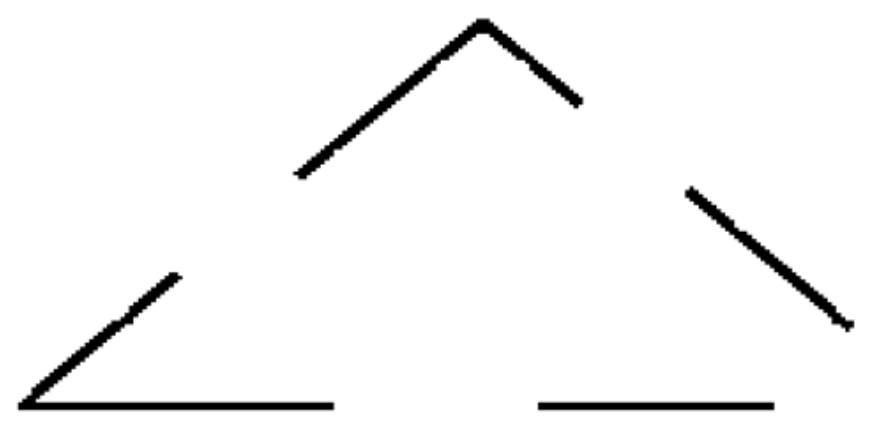

Fonte: desenvolvido pelo autor a partir de Gomes Filho (2009).

Tendo essa base conceitual como suporte, que será devidamente ampliada ao longo do processo de construção, esta pesquisa prevê desenvolvimento em, no mínimo, 24 meses, estando organizada em fases que permite a clara identificação das ações empreendidas.

Para cumprir os objetivos, será utilizada como base metodológica, conforme citado acima, o estudo de caso descritivo, que, conforme Yin (2005 p. 32) “é uma investigação empírica, que investiga um fenômeno contemporâneo dentro de seu contexto da vida real, especialmente quando os limites entre fenômeno e contexto não estão claramente definidos".

Assim, opta-se por tal metodologia por ofertar flexibilidade de instrumentos e uma visão geral, ampla dos objetos em sua relação e correlação em seu ambiente de circulação. 


\section{CONSIDERAÇÕES FINAIS}

Observando, então, a variedade e a variabilidade dos objetos e elementos nas telas, tendo em conta os princípios de formação da percepção fornecidos pela Gestalt, será possível compreender o tipo de reação e ação pensada, planejada pelo designer, bem como a usabilidade dos aplicativos Android.

Será, também, possível analisar os elementos, formatos e lógicas de desenvolvimento das interfaces frente a grande variedade de formatos de telas, identificando assim as estratégias de construção e desenvolvimento aplicados pelos designers das interfaces de aplicativos para dispositivos Android, estabelecendo um conjunto de regras e procedimentos que auxiliem no desenvolvimento de novos aplicativos. E, logo, na formação ou aprimoramento de profissionais neste campo de atividades. 
A tela dos dispositivos Android... responsivo

STEFFEN, C.

\section{REFERÊNCIAS}

1. CYBIS, Walter; BETIOL, Adriana Holtz; FAUST, Richard. Ergonomia e usabilidade: conhecimentos, métodos e aplicações. 2. ed. São Paulo: Novatec, 2010.

2. FRAGOSO, Suely Dadalti. Mídias digitais: revisão histórico-conceitual. São Leopoldo, RS: UNISINOS, 2002. Documento Hipertextual - material de apoio da disciplina: Mídias Digitais, Mestrado em Ciências da Comunicação.

3. GOMES FILHO, João. Gestalt do objeto: sistema de leitura visual da forma. 9. ed. São Paulo: Escrituras, 2009.

4. INTERNATIONAL ORGANIZATION FOR STANDARDIZATION. ISO/IEC 91261: software engineering - product quality - part 1: quality model. Geneva, Switzerland: ISO, 2001. Disponível em: http//www.iso.org. Acesso em: 1 set. 2014.

5. MARCOTE, Ethan. Responsive web design. 2010. Disponível em http:// alistapart.com/article/responsive-web-design. Acesso em: 1 set. 2014.

6. MCLUHAN, Marshall. Os meios de comunicação: como extensões do homem. 18. ed. São Paulo: Cultrix, 2012.
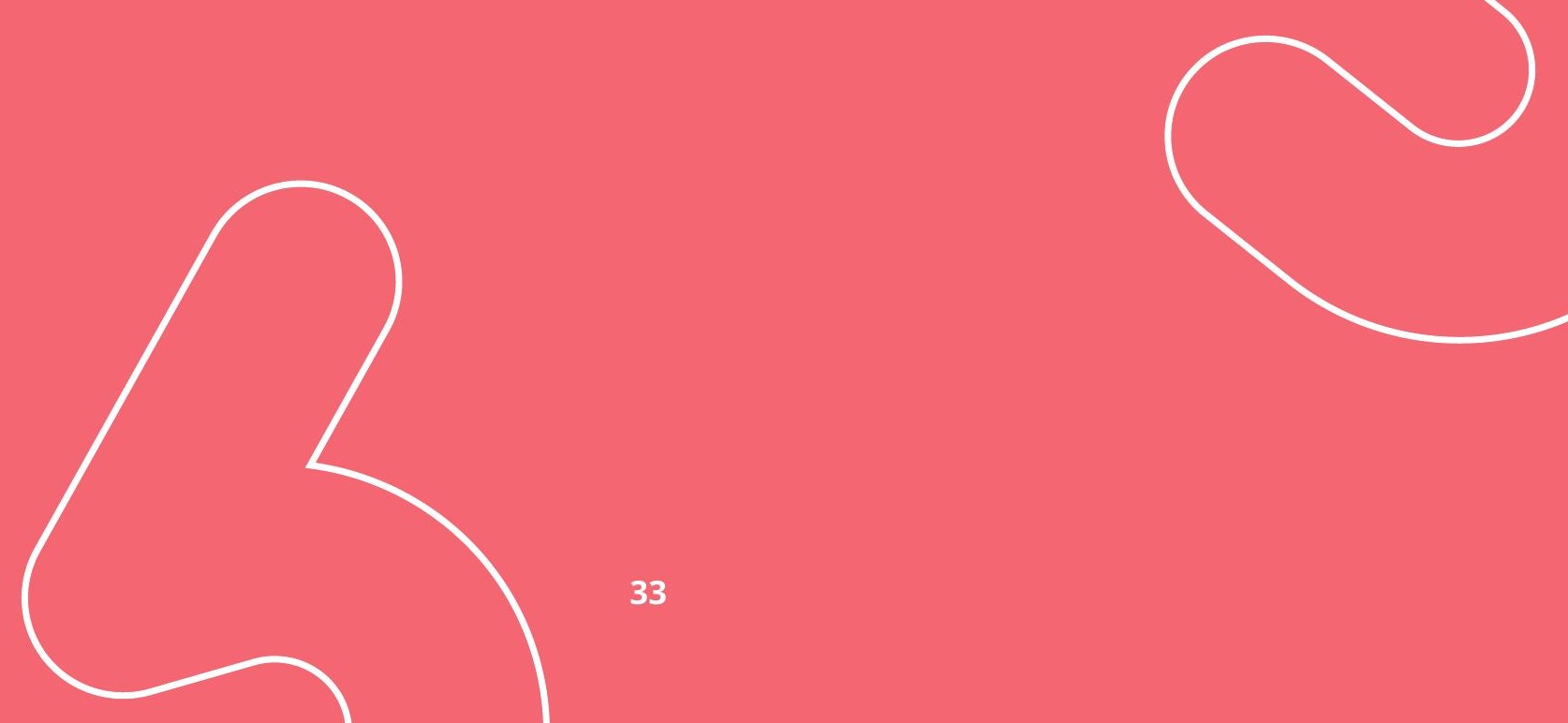
Projética, Londrina, v. 11, n. 2, p. 15-34, agosto 2020

7. NIELSEN, Jakob; LORANGER, Hoa. Usabilidade na web. Rio de Janeiro: Elsevier, 2007.

8. NORMAN, Donald A. Design emocional: por que adoramos (ou detestamos) os objetos do dia-a-dia. Rio de Janeiro: Rocco, 2008.

9. PERRIAULT, Jacques. Las maquinas de comunicar y su utilización lógica. Barcelona: GEDISA, 1991.

10. YIN, Robert K. Estudo de caso: planejamento e métodos. 3. ed. Porto Alegre: Bookman, 2005.
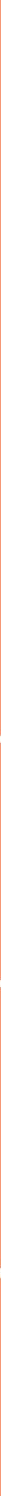